\title{
Insights into the Activity and Deactivation of the Methanol-to-Olefins Process over Different Small-Pore Zeolites As Studied with Operando UV-vis Spectroscopy
}

\author{
Joris Goetze, $^{\dagger}$ Florian Meirer, $^{\dagger}$ Irina Yarulina, $^{\ddagger}$ Jorge Gascon, $^{\ddagger}{ }^{\ddagger}$ Freek Kapteijn, ${ }^{\ddagger}$ J0 Javier Ruiz-Martínez, \\ and Bert M. Weckhuysen* ${ }^{* \dagger}$
}

$\dagger$ Inorganic Chemistry and Catalysis, Debye Institute for Nanomaterials Science, Utrecht University, Universiteitsweg 99 ,
3584 CG Utrecht, The Netherlands

${ }^{\ddagger}$ Catalysis Engineering, Chemical Engineering Department, Delft University of Technology, Van der Maasweg 9, 2629 HZ Delft,

The Netherlands

\section{Supporting Information}

ABSTRACT: The nature and evolution of the hydrocarbon pool (HP) species during the Methanol-to-Olefins (MTO) process for three small-pore zeolite catalysts, with a different framework consisting of large cages interconnected by small eight-ring windows (CHA, DDR, and LEV) was studied at reaction temperatures between 350 and $450{ }^{\circ} \mathrm{C}$ using a combination of operando UV-vis spectroscopy and online gas chromatography. It was found that small differences in cage size, shape, and pore structure of the zeolite frameworks result in the generation of different hydrocarbon pool species. More specifically, it was found that the large cage of CHA results in the formation of a wide variety of hydrocarbon pool species, mostly alkylated benzenes and naphthalenes. In the DDR cage, 1-methylnaphthalene is preferentially formed, while the small

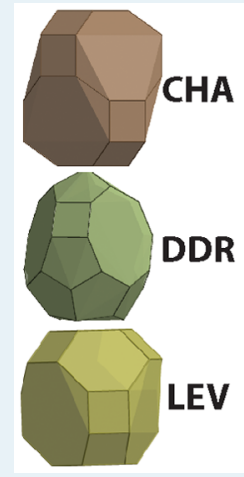

Retained Hydrocarbons in MTO

CHA Methanol Conversion

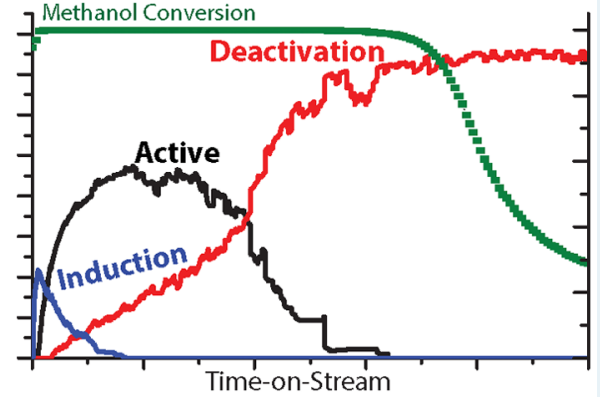

LEV cage generally contains fewer hydrocarbon pool species. The nature and evolution of these hydrocarbon pool species was linked with the stage of the reaction using a multivariate analysis of the operando UV-vis spectra. In the 3-D pore network of $\mathrm{CHA}$, the reaction temperature has only a minor effect on the performance of the MTO catalyst. However, for the 2-D pore networks of DDR and LEV, an increase in the applied reaction temperature resulted in a dramatic increase in catalytic activity. For all zeolites in this study, the role of the hydrocarbon species changes with reaction temperature. This effect is most clear in $\mathrm{DDR}$, in which diamantane and 1-methylnaphthalene are deactivating species at a reaction temperature of $350{ }^{\circ} \mathrm{C}$, whereas at higher temperatures diamantane formation is not observed and 1-methylnaphthalene is an active species. This results in a different amount and nature of coke species in the deactivated catalyst, depending on zeolite framework and reaction temperature.

KEYWORDS: methanol-to-olefins, zeolites, operando, UV-vis spectroscopy, deactivation, coke formation, chemometrics

\section{INTRODUCTION}

Lower olefins $\left(\mathrm{C}_{2}-\mathrm{C}_{4}\right)$ are important base chemicals used in many applications, such as the catalytic production of various plastics, including high- and low-density polyethylene (HDPE, LLDPE) and polypropylene (PP). ${ }^{1}$ Traditionally, these lower olefins are produced from crude oil fractions. ${ }^{2}$ However, in view of a more sustainable future and the depletion of crude oil reserves, alternative sources of energy and materials have to be developed. The production of fuels and lower olefins from sources other than crude oil, for example, via methanol, can play an important role in the change to a society that is less dependent on crude oil. This process is called the Methanol-to-Hydrocarbon (MTH) process. Methanol can be synthesized from synthesis gas, which can be produced from virtually any carbon source. This means that not only coal and natural gas can be used in the MTH process, but also more sustainable resources, such as biomass and waste. The MTH process is catalyzed by zeolite or zeotype catalysts, which contain Brønsted acid sites that provide the catalytic activity. Zeolites have a well-defined micropore structure, and the pore dimensions of these materials are important in determining the final product distribution. When the main products of the MTH process are lower olefins, the process is referred to as Methanol-to-Olefins (MTO). ${ }^{3}$ Zeolite frameworks with medium-sized pores, such as MFI (i.e., ZSM-5), generally yield products in the gasoline range, but the selectivity toward lower olefins can be increased by tuning the properties of the catalyst and the reaction conditions. ${ }^{3-5}$ Small-pore frameworks, such as CHA (i.e., SAPO-34 and SSZ-13), are very selective

Received: December 26, 2016

Revised: April 23, 2017

Published: May 16, 2017 
toward the formation of lower olefins, because larger organics that are formed inside the zeolite cannot exit as reaction products. Recently, besides the CHA framework, other smallpore zeolites, such as LEV, DDR, AEI, RHO, KFI, ITH and AFX, have also been identified as interesting candidates for the MTO process. ${ }^{6-14}$ Small differences in the framework topology of these small-pore zeolites can have a large effect on both product selectivity and the intermediate species involved in the MTO process. ${ }^{6,15,16}$ For instance, DDR catalysts exhibit a high selectivity toward ethylene and propylene over $C_{2}$ and $C_{3}$ paraffins due to their pore structure.

Since the beginning of this century, the most widely accepted mechanism for MTO processes is the hydrocarbon pool (HP) mechanism., ${ }^{3,18}$ In this mechanism, the active site for the production of olefins is the combination of a Brønsted acid site and a pool of retained hydrocarbon species, which can be either neutral or charged by the zeolite framework. However, the exact nature of the hydrocarbon pool and detailed reaction mechanism are still the subject of debate, and depend on the type of zeolite framework, i.e., the exact mechanism for MTO over mediumpore zeolites, such as MFI, differs from the mechanism for small-pore zeolites, such as CHA.,19-23 The main reason for deactivation of MTO catalysts is the formation of carbonaceous deposits, or coke, during the reaction. These carbonaceous deposits can originate from hydrocarbon pool species which are not active in producing olefins anymore, or they can be formed at the external surface of the zeolite crystals. Therefore, a distinction can be made between deactivation caused by filling all zeolite pores with carbonaceous deposits, and by coke located at the external surface of the zeolite, which prevents access to the zeolite pores. $^{3,5,23,24}$
In situ and operando spectroscopy methods, such as UV-vis, IR and X-ray spectroscopy, are very useful tools for following the formation of these hydrocarbon pool species inside zeolite materials during the conversion of methanol or other reactants. This can lead to a better understanding of the mechanism and deactivation of zeolite-based catalysts. ${ }^{3,25-28}$ The hydrocarbon pool consists of volatile species, such as olefins and (poly)enyl species, as well as neutral and charged aromatic structures, which absorb ultraviolet and visible light. The species that are retained and accumulate inside the zeolite can be followed especially well with spectroscopic methods. Previously, UV-vis spectroscopy has been applied to follow the formation of coke during different catalytic reactions including MTO, both on bulk samples ${ }^{29-31}$ and on the individual particle level. ${ }^{32,33}$ Besides coke deposits, MTO intermediates have also been studied with in situ UV-vis spectroscopy, relating the UV-vis spectra of the catalyst material to the stage of the reaction. $22,25,29,31,34-38$

In this study, operando UV-vis spectroscopy (i.e., UV-vis spectroscopy combined with online product analysis), as well as chemical analysis of the carbonaceous deposits that are formed during the conversion of methanol over small-pore zeolites, was applied to gain more insight into the MTO mechanism as well as into the evolution of the hydrocarbon pool. More specifically, a comparison was made between three different zeolite frameworks that consist of large cages that are interconnected by eightring windows, i.e., CHA (zeolite SSZ-13), DDR (zeolite Sigma-1), and LEV (zeolite Nu-3). The dimensions and shapes of these zeolites and their cages are shown in Table 1. By comparing the aluminosilicate versions of the selected zeolite frameworks, the acid strength of the materials was kept constant in order to

Table 1. Framework Properties and Acidity of the Zeolite Materials under Investigation

\begin{tabular}{|c|c|c|c|}
\hline & CHA & DDR & LEV \\
\hline Cage dimensions $\left(\AA^{2}\right)^{52}$ & $\begin{array}{l}10.9 \AA \\
\end{array}$ & (1) & 4 \\
\hline Window dimensions $\left(\AA^{2}\right)^{52}$ & $3.8 \times 3.8$ & $3.6 \times 4.4$ & $3.8 \times 4.4$ \\
\hline Crystal shape & cubic & platelet & cuboid \\
\hline Pore structure (2-D/3-D) & $3-\mathrm{D}$ & $2-\mathrm{D}$ & $2-\mathrm{D}$ \\
\hline $\begin{array}{l}\text { Si:Al ratio (measured with } \\
\text { ICP/theoretical) }\end{array}$ & $59 / 60$ & $50 / 30$ & n.d. $/ 30$ \\
\hline $\begin{array}{l}\text { Amount of acid sites (mmol } \\
\mathrm{NH}_{3} / \mathrm{g} \text { cat.) }\end{array}$ & 0.29 & 0.34 & 0.80 \\
\hline Acid sites per cage & 0.20 & 0.39 & 0.41 \\
\hline $\mathrm{NH}_{3}$-TPD peak $1\left({ }^{\circ} \mathrm{C}\right)$ & 167 & 167 & 167 \\
\hline $\mathrm{NH}_{3}$-TPD peak $2\left({ }^{\circ} \mathrm{C}\right)$ & 435 & 405 & 425 \\
\hline $\begin{array}{l}\text { IR shift of Brønsted } \mathrm{OH} \text {-peak } \\
\text { upon } \mathrm{CO} \text {-adsorption }\left(\mathrm{cm}^{-1}\right)\end{array}$ & $315 \mathrm{~cm}^{-1}$ & $316 \mathrm{~cm}^{-1}$ & $307 \mathrm{~cm}^{-1}$ \\
\hline
\end{tabular}


make the comparison based on the differences in framework structure as relevant as possible.

\section{EXPERIMENTAL SECTION}

2.1. Materials and Their Synthesis. The synthesis procedures of the zeolites under study were taken from existing recipes with some modifications from the open literature. ${ }^{39-42}$ In all cases, Ludox HS-40 was used as silica source and $\mathrm{NaAlO}_{2}$ as alumina source. All chemicals were purchased from SigmaAldrich unless specified otherwise and were used without any further purification.

Zeolite SSZ-13 with CHA topology was synthesized according to $\mathrm{Zhu}$ et al. ${ }^{41}$ using $N, N, N$-trimethyl-1-adamantammonium hydroxide (TMAdaOH) provided by SACHEM Inc. as structure directing agent (SDA) and gel composition TMAdaOH/ $\mathrm{NaOH} / \mathrm{SiO}_{2} / \mathrm{Al}_{2} \mathrm{O}_{3} / \mathrm{H}_{2} \mathrm{O}=20: 20: 102.8: 2.2: 4400$. At first, $25 \%$ of TMAdaOH solution was mixed with a solution of $0.077 \mathrm{~g}$ of sodium aluminate and $0.32 \mathrm{~g}$ of sodium hydroxide in $8.51 \mathrm{~g}$ of deionized water. When the solution became clear, $6.95 \mathrm{~g}$ of Ludox HS-40 and $17.26 \mathrm{~g}$ of deionized water were added and kept for aging for $4 \mathrm{~h}$ under constant stirring. The obtained mixture was transferred to autoclaves and subjected to hydrothermal synthesis at $160{ }^{\circ} \mathrm{C}$ for $120 \mathrm{~h}$.

Zeolite Sigma-1 with DDR topology was synthesized as described in Stewart's patent ${ }^{43}$ using 1-adamantylamine (ADA) as $\mathrm{SDA}$ and gel composition of $\mathrm{ADA} / \mathrm{Na}_{2} \mathrm{O} / \mathrm{SiO}_{2} / \mathrm{Al}_{2} \mathrm{O}_{3} / \mathrm{H}_{2} \mathrm{O}=$ 20:3:60:1:2400. Crystals were obtained via hydrothermal synthesis of the gel in an autoclave at $180^{\circ} \mathrm{C}$ for $144 \mathrm{~h}$. The detailed synthesis procedures can be found elsewhere. ${ }^{17,44}$

Zeolite Nu-3 with LEV topology was also synthesized according to Stewart's patent ${ }^{40}$ using $\mathrm{ADA}$ as SDA and a gel composition of $\mathrm{ADA} / \mathrm{Na}_{2} \mathrm{O} / \mathrm{SiO}_{2} / \mathrm{Al}_{2} \mathrm{O}_{3} / \mathrm{H}_{2} \mathrm{O}=$ 20:3.5:60:3.5:2400. In a typical synthesis, $10.66 \mathrm{~g}$ of Ludox HS-40 was mixed with $3.6 \mathrm{~g}$ of $\mathrm{ADA}$ and $30.4 \mathrm{~g}$ of deionized water and stirred for $15 \mathrm{~min}$, followed by the addition of $0.67 \mathrm{~g}$ of sodium aluminate dissolved in $14.64 \mathrm{~g}$ of deionized water. The obtained mixture was aged for another $30 \mathrm{~min}$ and then transferred to autoclaves and subjected to hydrothermal synthesis at $200{ }^{\circ} \mathrm{C}$ for $160 \mathrm{~h}$.

The obtained zeolite crystals were thoroughly washed with deionized water and dried overnight. All three zeolite materials obtained by the above-described recipes were further subjected to ball-milling following the exact methodology as described elsewhere. ${ }^{17}$ Subsequent syntheses of zeolites with CHA, DDR, and LEV topology were performed by seed-assisted growth using the ball-milled crystals with corresponding topology as seed solution $(0.1 \mathrm{wt} \%)$. The amount of $\mathrm{Al}$ in each gel composition was modified in such a way to obtain the desired $\mathrm{Si} / \mathrm{Al}$ ratio, whereas the synthesis time was reduced to $16 \mathrm{~h}$. The as-synthesized crystals were calcined for $10 \mathrm{~h}$ at $650{ }^{\circ} \mathrm{C}$ independently on the zeolite topology and were converted to their protonic forms by triple ion-exchange in aqueous $\mathrm{NH}_{4} \mathrm{NO}_{3}$ solution $(1 \mathrm{M}$, $80^{\circ} \mathrm{C}, 2 \mathrm{~h}, 100 \mathrm{~mL}$ per gram of zeolite) followed by calcination at $550{ }^{\circ} \mathrm{C}$.

The methanol, HPLC grade (99.99\% pure), used for catalytic testing was obtained from Acros Organics.

2.2. Materials Characterization. Temperature-programmed desorption of $\mathrm{NH}_{3}\left(\mathrm{NH}_{3}\right.$-TPD) was performed on a Micromeritics Autochem II 2920 equipped with a TCD detector. Before the adsorption of $\mathrm{NH}_{3}$ at $100^{\circ} \mathrm{C}$, ca. $100 \mathrm{mg}$ of zeolite was heated to $600{ }^{\circ} \mathrm{C}$ in $\mathrm{N}_{2}$ flow for $1 \mathrm{~h}$. After that, the sample was flushed with $\mathrm{N}_{2}$ for $1 \mathrm{~h}$ at $100{ }^{\circ} \mathrm{C}$ to remove physisorbed $\mathrm{NH}_{3}$.
Subsequently, temperature-programmed desorption of the adsorbed $\mathrm{NH}_{3}$ was performed at a rate of $5{ }^{\circ} \mathrm{C} / \mathrm{min}$ to $600{ }^{\circ} \mathrm{C}$.

$\mathrm{CO}$ adsorption followed by IR spectroscopy was performed on self-supporting catalyst wafers of ca. $15 \mathrm{mg}$, which were placed in a vacuum cell. After heating the wafer in vacuum for $1 \mathrm{~h}$ at $400{ }^{\circ} \mathrm{C}$, the cell was cooled to $-196{ }^{\circ} \mathrm{C}$ using liquid $\mathrm{N}_{2}$. After that, the $\mathrm{CO}$ pressure was gradually increased to ca. $10 \mathrm{mbar}$ and IR spectra were recorded with a PerkinElmer 2000 FT-IR spectrometer.

To determine the $\mathrm{Si} / \mathrm{Al}$ ratio of the zeolites, the samples were digested in an aqueous mixture of $1 \% \mathrm{HF}$ and $1.25 \% \mathrm{H}_{2} \mathrm{SO}_{4}$. Subsequently, elemental analysis was done by inductively coupled plasma-optical emission spectrometry (ICP-OES), on a PerkinElmer Optima 4300 DV instrument.

2.3. Operando UV-vis spectroscopy. Catalytic testing was performed using $50 \mathrm{mg}$ of catalyst in a quartz, rectangular fixed-bed reactor $(\mathrm{ID}=6 \mathrm{~mm} \times 3 \mathrm{~mm})$ with a weight hourly space velocity (WHSV) of $1 \mathrm{~g} \mathrm{~g}^{-1} \mathrm{~h}^{-1}$. A sieve fraction of $0.2-0.4 \mathrm{~mm}$ zeolite particles was used, and the resulting bed length was ca. $5 \mathrm{~mm}$. A He flow with a methanol saturation of ca. $13 \%$ was obtained by flowing $\mathrm{He}$ as carrier gas through a saturator containing methanol at $20{ }^{\circ} \mathrm{C}$. Operando UV-vis spectra were obtained using an AvaSpec 2048L spectrometer connected to a high-temperature UV-vis optical fiber probe, which was used to collect spectra in reflection mode. Online analysis of the reactant and reaction products was performed using an Interscience Compact GC, equipped with an Rtx-wax and Rtx- 1 column in series and an Rtx-1, Rt-TCEP and $\mathrm{Al}_{2} \mathrm{O}_{3} / \mathrm{Na}_{2} \mathrm{SO}_{4}$ in series, both connected to an FID detector. Details of the experimental setup can be found in earlier papers of the Inorganic Chemistry and Catalysis group of Utrecht University. ${ }^{29,45-47}$

Methanol conversion was calculated as follows:

$$
\text { methanol conversion }=\frac{\left[\mathrm{MeOH}_{\mathrm{in}}\right]-\left[\mathrm{MeOH}_{\mathrm{out}}\right]}{\left[\mathrm{MeOH}_{\mathrm{in}}\right]}
$$

The yield of the hydrocarbons was based on carbon atoms and calculated using

$$
\text { Yield }_{\mathrm{C}_{n} \mathrm{H}_{m}}=\frac{\mathrm{n}\left[\mathrm{C}_{n} \mathrm{H}_{m}\right]}{\left[\mathrm{MeOH}_{\mathrm{in}}\right]}
$$

2.4. Characterization of Retained Hydrocarbons. Hydrocarbons trapped inside the catalyst material after catalytic testing were analyzed by dissolving the zeolite framework, followed by extracting the hydrocarbons using $\mathrm{CH}_{2} \mathrm{Cl}_{2}$. Typically, $15 \mathrm{mg}$ of spent catalyst was dissolved in $1 \mathrm{~mL}$ of a $45 \% \mathrm{HF}$ solution in a Teflon container. The organic compounds were extracted from the water phase two times by the addition of $1 \mathrm{~mL}$ $\mathrm{CH}_{2} \mathrm{Cl}_{2}$. Analysis of the extracted phase was performed on a Shimadzu GCMS-QP2010 GC/MS system, equipped with an Agilent VF-5 ms column.

To quantify the amount of coke formed during methanol conversion, thermogravimetric analysis (TGA) was performed on the spent catalyst samples. Ca. $10 \mathrm{mg}$ of spent catalyst was heated in $\mathrm{O}_{2}$ flow to $800{ }^{\circ} \mathrm{C}$ to burn off the carbonaceous deposits, after drying in $\mathrm{N}_{2}$ flow for $1 \mathrm{~h}$ at $150{ }^{\circ} \mathrm{C}$. The weight loss during this process was recorded using a PerkinElmer Pyris 1 TGA attached to a mass spectrometer.

\section{RESULTS AND DISCUSSION}

3.1. Bulk Characterization. Table 1 summarizes the bulk characterization data of the zeolite materials under study. The crystal size of the three samples was determined by SEM, as 
shown in Figure S1, and was typically between 200 and $800 \mathrm{~nm}$. The Si/Al ratio of the material was measured using ICP-OES. The acidity of the different catalyst materials was assessed with $\mathrm{NH}_{3}$-TPD and by IR spectroscopy using $\mathrm{CO}$ as a probe molecule. The $\mathrm{NH}_{3}$ desorption curves of all of the samples show two peaks, one low-temperature peak at $167{ }^{\circ} \mathrm{C}$ and one high-temperature peak above $400{ }^{\circ} \mathrm{C}$, corresponding to weak and strong acid sites, respectively (Figure S2). ${ }^{48}$ The total amount of acid sites was obtained by integrating the area under the desorption curves and strongly corresponds to the amount of Brønsted acid sites calculated from the $\mathrm{Si} / \mathrm{Al}$ ratio of the catalyst (Table 1). The $\mathrm{Si} / \mathrm{Al}$ ratio is lower for DDR and LEV than for $\mathrm{CHA}$, resulting in a higher concentration of accessible Brønsted acid sites. However, since the number of acid sites per cage is still well below 1 , the chance that a cage contains more than one acid site is low, so this is not expected to change the mechanism of the reaction. The temperature for the hightemperature desorption peak is slightly lower for DDR than for the other two framework structures (i.e., 405 vs 435 and $425{ }^{\circ} \mathrm{C}$, see Table 1 and Figure S2), which could indicate that the strength of the Brønsted acid sites in DDR is lower than in the other two zeolites. To verify this, the Brønsted acid strength was determined by performing $\mathrm{CO}$ adsorption at low temperatures, followed by IR spectroscopy (Figure S3). The shift of the IR peak originating from $\mathrm{OH}$-vibrations of Brønsted acid sites upon adsorption of $\mathrm{CO}$, which is measured under equilibrium conditions, gives a more precise indication of the acid strength. ${ }^{49}$ The measurements reveal a very similar acid strength for the three zeolite frameworks under study. On the basis of the above-discussed measurements, we can conclude that, for the purpose of this work, a comparison of the different zeolite frameworks based on their structural differences (i.e., their pore structure and cage size) the amount and strength of acid sites of the different frameworks show a good enough similarity.

3.2. Catalytic Performance. The catalytic activity of the different zeolite materials for the conversion of methanol into olefins was tested at three different reaction temperatures, i.e., 350,400 , and $450{ }^{\circ} \mathrm{C}$. The conversion of methanol and formation of products were monitored using online GC analysis and are discussed in this section, whereas the formation of the hydrocarbon species inside the zeolite crystals was analyzed using operando UV-vis spectroscopy. The latter will be discussed in a later section. However, it is important to stress that both types of measurements were done in the same experimental setup and at the same time; in other words, the reported experiments are performed under true operando spectroscopy conditions.

During the experiment, all catalyst materials exhibit a short induction period, followed by a period in which $100 \%$ of the methanol is converted. During this phase, methanol is converted into the main products: ethylene, propylene, and butylene. In addition, small amounts of dimethyl ether (DME), $\mathrm{C}_{5}$ olefins, and paraffins are formed. Methanol conversion and yields of $\mathrm{C}_{2}-\mathrm{C}_{4}$ olefins are shown in Figure 1. The maximum total yield of $\mathrm{C}_{2}-\mathrm{C}_{4}$ olefins follows the order: $\mathrm{CHA}>\mathrm{DDR}>\mathrm{LEV}$. For LEV, the total yield of $\mathrm{C}_{2}-\mathrm{C}_{4}$ olefins is lower compared to the other two frameworks, and the other products are mainly $\mathrm{C}_{5}$ olefins and DME. Small amounts of paraffins, mainly methane and propylene, are formed for all frameworks and their yields are presented in Figure S4. Larger products, such as aromatics, that are unable to leave the material because of the size of the eightring windows, are retained inside the zeolite. In general, the formation of propylene stays relatively constant with increasing time-on-stream and with reaction temperature during the period of $100 \%$ conversion. However, the formation of ethylene increases with increasing reaction temperature and also with increasing a)

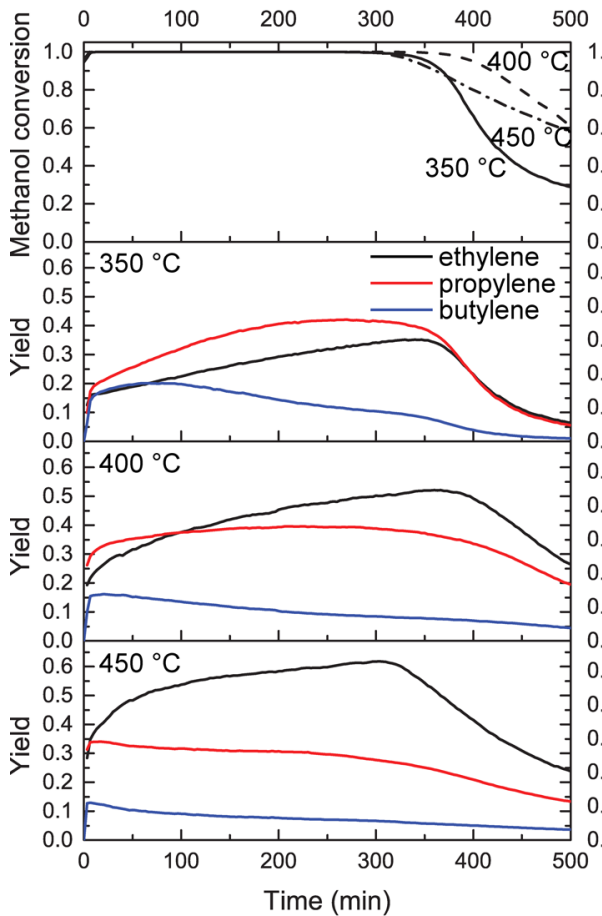

b) c)
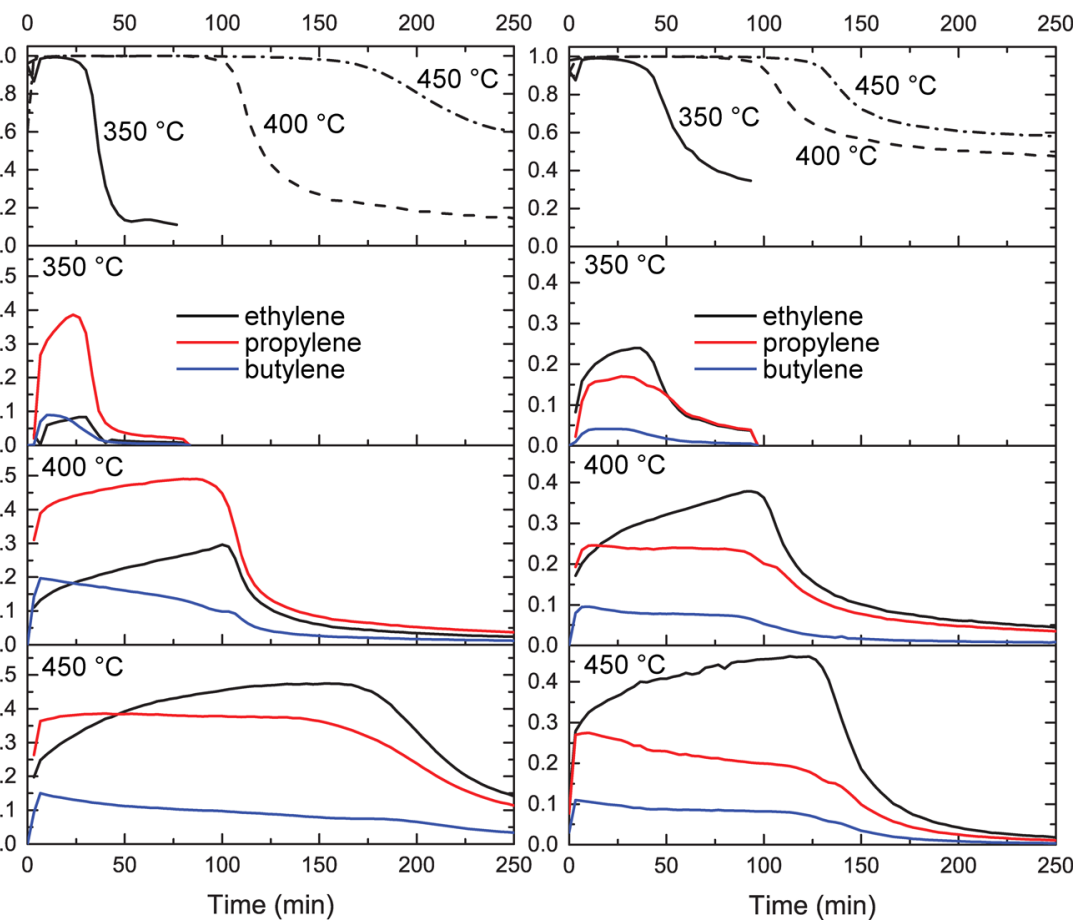

Figure 1. Catalytic performance and yields of $\mathrm{C}_{2}-\mathrm{C}_{4}$ olefins during the conversion of methanol for (a) CHA, (b) DDR, and (c) LEV zeolites at a reaction temperature of 350,400 , and $450{ }^{\circ} \mathrm{C}$ at a WHSV of $1 \mathrm{~h}^{-1}$. 
time-on-stream. Simultaneously, the butylene yield decreases with increasing time-on-stream. After this period, the activity drops quickly. At that point, we observe that the remaining conversion of methanol is toward the production of DME. Since DME is often used as a reactant in the MTO process, the catalyst is not considered active anymore when DME is the main product formed.

We defined the start of deactivation as the point where methanol conversion drops below $90 \%$. The amount of methanol that is converted before deactivation, which is summarized in Table 2, is higher for CHA than for DDR and LEV. A combination

Table 2. Catalytic Performance of the Different Zeolite Framework Structures in the Methanol-to-Olefins (MTO) Process and Related Coke Amount of the Spent Catalyst Sample, Measured with Thermogravimetric Analysis (TGA)

\begin{tabular}{|c|c|c|c|c|c|c|}
\hline \multirow[b]{2}{*}{$\mathrm{T}\left({ }^{\circ} \mathrm{C}\right)$} & \multicolumn{3}{|c|}{ 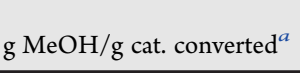 } & \multicolumn{3}{|c|}{$\begin{array}{c}\text { coke level of spent catalyst (wt } \\
\%)\end{array}$} \\
\hline & $\mathrm{CHA}$ & DDR & LEV & $\mathrm{CHA}$ & DDR & LEV \\
\hline 350 & 6.2 & 0.6 & 0.7 & 20.6 & 9.3 & 13.4 \\
\hline 400 & 7.0 & 1.8 & 1.7 & 19.7 & 11.5 & 15.0 \\
\hline 450 & 6.1 & 3.1 & 2.3 & 16.9 & 11.6 & 14.3 \\
\hline
\end{tabular}

${ }^{a}$ Until deactivation, i.e., methanol conversion below $90 \%$.

of different factors can explain the higher stability for CHA. First of all, CHA has the highest volume of cages per gram of material, which results in a longer active period before all pores of the material are filled with deactivating species. ${ }^{50}$ Also, CHA contains fewer acid sites per cage, which is known to have a beneficial effect on the lifetime of zeolite MTO catalysts. ${ }^{3,51}$ Finally, the 3-D pore structure of CHA leads to less diffusion limitations, which makes it easier for both methanol and products to diffuse through the crystals and results in a higher stability against pore blockage. Furthermore, the catalytic stability of DDR and LEV increases at higher reaction temperatures, whereas for CHA the stability is relatively independent of the reaction temperature. This indicates that the mechanism of deactivation is different for the different frameworks and at different reaction temperatures.

3.3. Analysis of the Retained Hydrocarbons. To quantify the amount of coke formed in the zeolite catalysts, the spent catalyst samples were analyzed using thermogravimetric analysis (TGA) after removing them from the operando spectroscopy reactor setup. In an $\mathrm{O}_{2}$ flow, the spent samples were heated to $800^{\circ} \mathrm{C}$, resulting in the combustion of the retained hydrocarbon species. The total weight loss during this process is summarized in Table 2 and was used to measure to what extent the pores of the spent zeolite catalyst were filled. The maximum amount of carbonaceous deposits that can fit inside the pores of the three zeolite frameworks was calculated, assuming that a single DDR cage can accommodate two benzene molecules or one heavily branched coke molecule. ${ }^{7}$ The cage volumes were calculated considering the cages as cylinders, with the dimensions reported in Table 1 . Based on this, the maximum amount of coke is ca. 17 wt \% for CHA, ca. 12 wt \% for DDR and ca. 15 wt \% for $\mathrm{LEV}^{52}$ Since the amount of coke in the deactivated catalyst samples of CHA for reaction temperatures of 350 and $400{ }^{\circ} \mathrm{C}$ is more than the amount that can fit inside the cages, it means that external coke also has to be present. This is supported by the high intensity of the IR-band at $3735 \mathrm{~cm}^{-1}$ for the CHA sample, indicating that more external acidity is present in CHA than in the other two frameworks, causing the formation of external coke.
The fact that more external coke is usually observed at higher reaction temperatures makes it likely that external coke will also play a role at a reaction temperature of $450{ }^{\circ} \mathrm{C}$. When external coke is also present in the CHA sample used for MTO at $450{ }^{\circ} \mathrm{C}$, it means that the pores of the catalyst are less filled than the samples used at 350 and $400{ }^{\circ} \mathrm{C}$. For the DDR and LEV zeolites, the amount of coke determined by TGA does not exceed the maximum amount that can be contained inside the cages. However, the presence of external coke cannot be ruled out. The pores of the DDR and LEV catalysts are completely filled with carbonaceous deposits at reaction temperatures of 400 and $450{ }^{\circ} \mathrm{C}$, whereas at a reaction temperature of $350^{\circ} \mathrm{C}$, the pores of the catalyst are not completely filled. In the cases where all pores are filled, it is likely to be the reason for deactivation of the catalyst, because it is impossible for methanol and the products to diffuse through the pores. In the cases where not all pores are filled, the reason for deactivation is assumed to be pore blockage, either by species in the outer regions of the catalyst particles, or by external coke.

Identification of the hydrocarbons inside of the deactivated catalyst was obtained by the dissolution of the spent zeolite samples in a concentrated HF solution, which allows the trapped hydrocarbon species to be analyzed. After dissolution of the framework, the hydrocarbons were extracted using dichloromethane (DCM) and GC/MS analysis of the solution was performed to give more insight in the chemical nature of the hydrocarbon pool species. With this method, only the soluble fraction of the coke can be analyzed. Large coke species, such as what forms at the outside of the zeolite, are not soluble in DCM and will not be extracted. ${ }^{53,54}$ The chromatograms are shown in Figure 2. Identification of most species was done using a library of mass spectra. However, to confirm the presence of 1-methylnaphthalene and diamantane, reference materials were used, which confirmed that these species were indeed present.

For CHA, the chromatograms show a broad distribution of species ranging from methylated benzenes to methylated naphthalenes and pyrene. At higher reaction temperatures, the average number of methyl groups on methylated naphthalenes is greater than the amount of methyl groups at lower reaction temperatures.

For DDR, the main species in the extracted hydrocarbons are alkylated naphthalenic species. At 400 and $450{ }^{\circ} \mathrm{C}$, the most abundant peak in the GC/MS spectrum is from 1-methylnaphthalene. At $350{ }^{\circ} \mathrm{C}$, the presence of diamantane is also observed in DDR. This is in agreement with previous studies in which similar diamondoid species have been reported during the conversion of methanol at low temperatures. ${ }^{55}$ The resemblance of diamantane with 1-adamantylamine, the SDA used in the synthesis of Sigma-1 DDR zeolites, is most likely the reason for the stability of these diamantane molecules in the DDR cages at low reaction temperatures. To ensure that the diamantane found in DDR was not formed from residual SDA, a fresh DDR sample was also dissolved in HF, but neither diamantane nor 1-adamantylamine was found.

For LEV, at reaction temperatures of 400 and $450{ }^{\circ} \mathrm{C}$, mainly naphthalene was present in the spent catalyst and almost no larger species were detected. Comparing the size of the LEV cage with the size of methylated naphthalene species, it is very likely that methylated naphthalenes do not fit inside the LEV cages. ${ }^{31}$ For the sample that catalyzed the reaction at $350{ }^{\circ} \mathrm{C}$, almost no naphthalene was extracted from the spent catalyst, but methylated benzenes were present. This indicates that the deactivation of 
a)

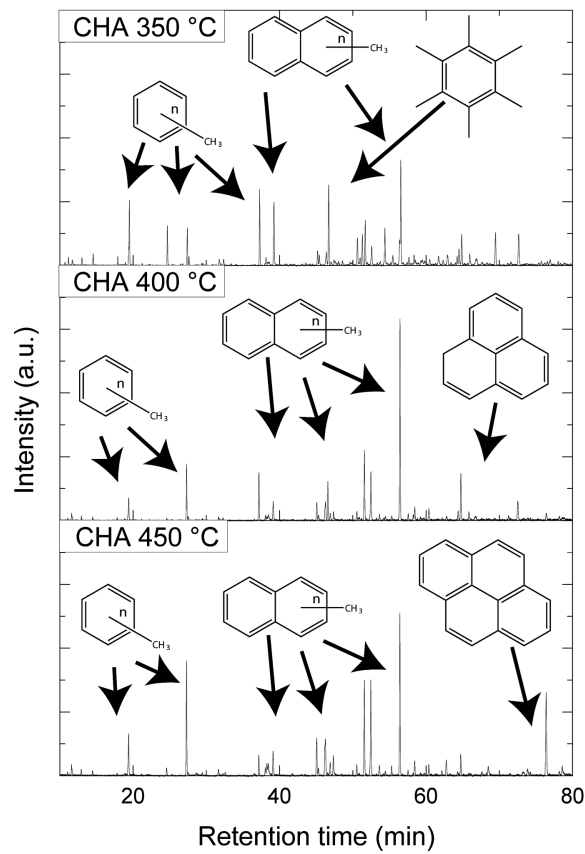

b)

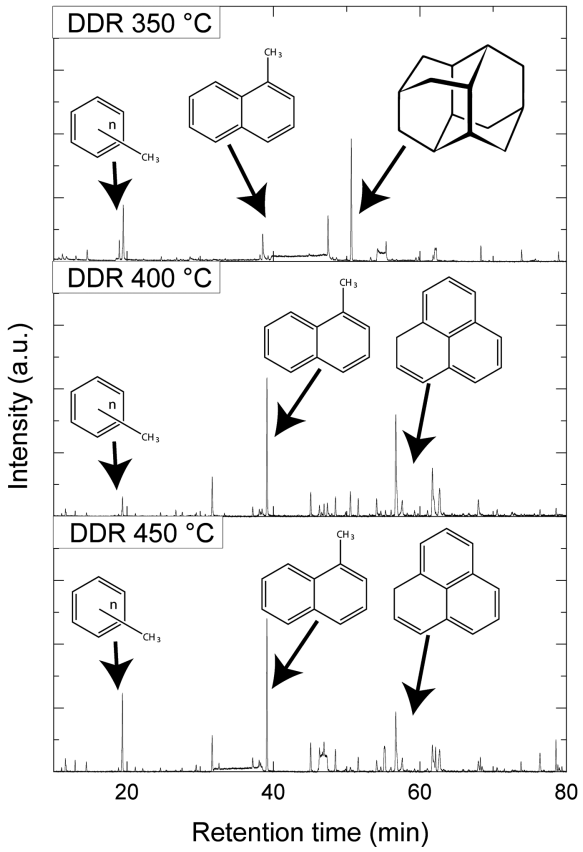

C)

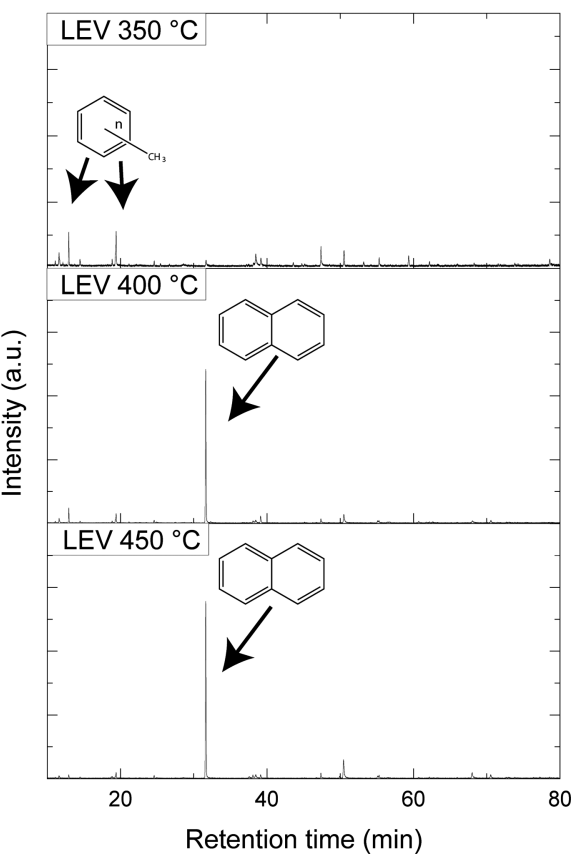

Figure 2. GC/MS results for the extracted species in (a) CHA, (b) DDR, and (c) LEV.

a)

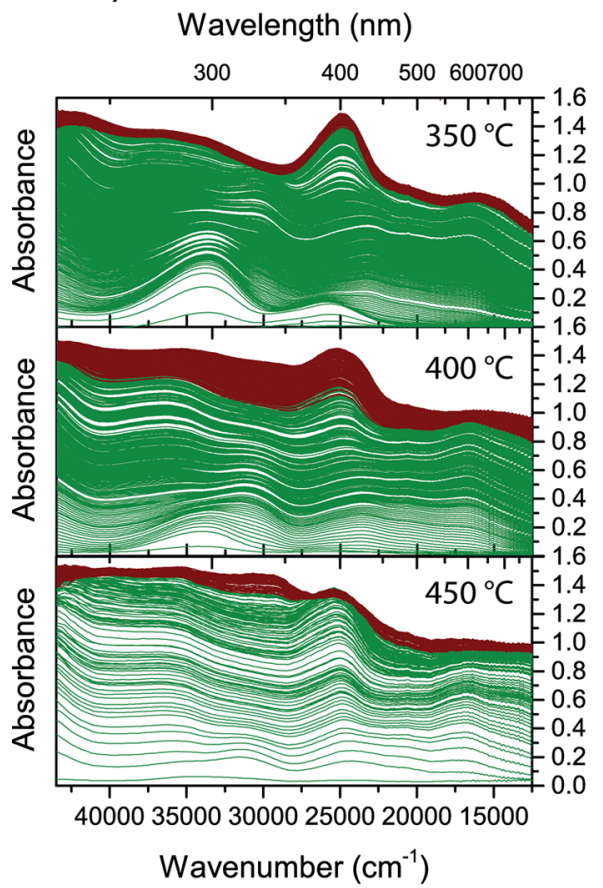

b) Wavelength $(\mathrm{nm})$

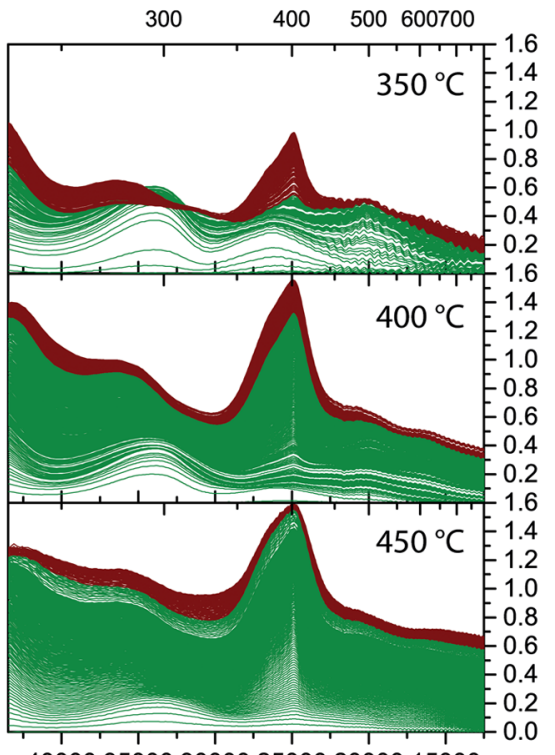

400003500030000250002000015000

Wavenumber $\left(\mathrm{cm}^{-1}\right)$
C)

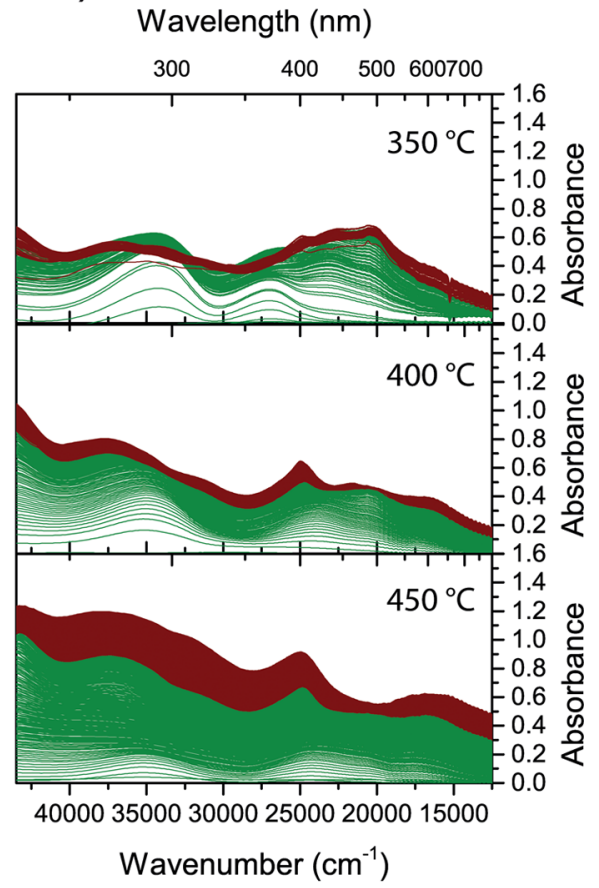

Figure 3. Operando UV-vis spectra during the conversion of methanol at 350,400 , and $450{ }^{\circ} \mathrm{C}$ over (a) CHA, (b) DDR, and (c) LEV zeolite. Red spectra indicate deactivation, i.e., methanol conversion lower than $90 \%$.

LEV at this reaction temperature might be caused by methylated benzene species.

3.4. Operando UV-vis Spectroscopy. Operando UV-vis spectroscopy was used to follow the formation of hydrocarbon species inside the zeolite catalyst. The operando UV-vis spectra during the conversion of methanol over CHA, DDR, and LEV are shown in Figure 3. In all experiments, an increase in absorbance with increasing time-on-stream is observed.
This indicates that, during the conversion of methanol, hydrocarbon species accumulate in the zeolite. In the first few spectra, while the first hydrocarbon species are formed inside the zeolite, the absorbance increases quickly and distinct absorption bands are visible. After this first period, the increase in absorbance slows down, and the absorption bands become broader. In all experiments, in addition to the formation of absorption bands, an increase in absorbance over the whole range of wavenumbers 


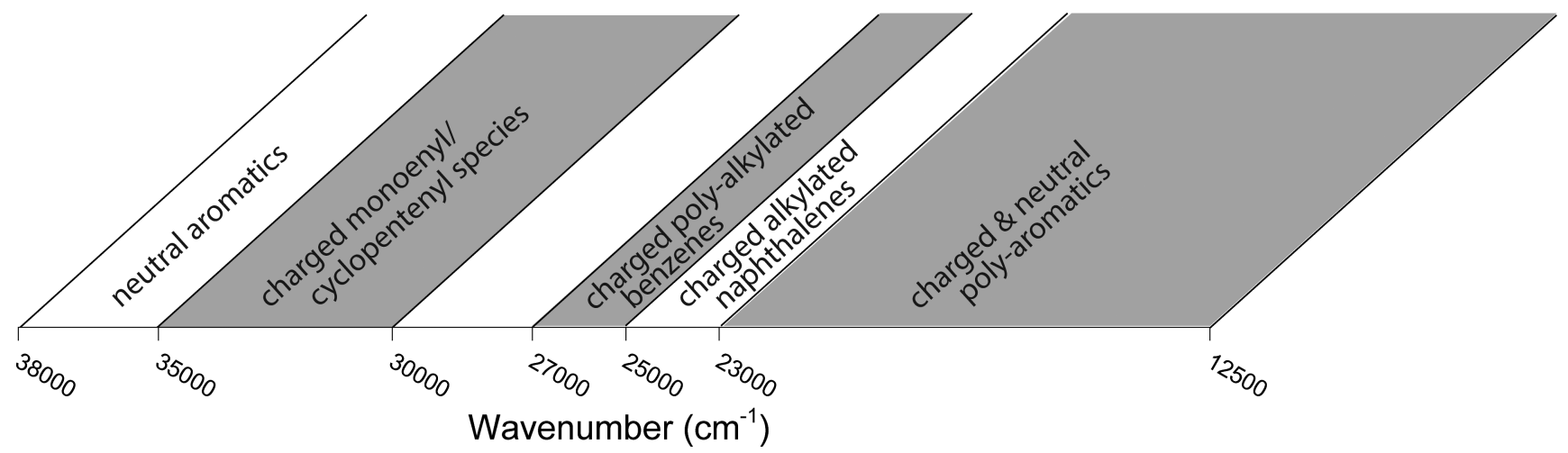

Figure 4. Overview of the UV-vis bands and related assignments of relevance to the Methanol-to-Hydrocarbon reaction over zeolite-based materials.

is observed with increasing time-on-stream. This darkening of the zeolite is most likely caused by the formation of larger carbonaceous deposits on the outer surface of the zeolite crystals due to external acidity of the zeolites.

On the basis of literature results, combined with the previously described GC/MS analysis of the retained species, assignments for the UV-vis absorbance bands were made, which are shown in Figure 4. ${ }^{22,29,34,37,56}$ In the UV region (i.e., above $35000 \mathrm{~cm}^{-1}$ ) neutral aromatic species absorb light, whereas at lower wavenumbers, absorption bands are assigned to conjugated carbocations, including protonated aromatics. With the increasing size of the conjugated carbocations, the absorption band occurs at lower wavenumbers. Neutral and charged polyaromatic species absorb at wavenumbers below $23000 \mathrm{~cm}^{-1}$.

For CHA, the reaction starts with the formation of bands around 34000 and $26000 \mathrm{~cm}^{-1}$, because of monoenyl species and charged polyalkylated benzene species. This is followed by the growth of the bands around 30500 and $23000 \mathrm{~cm}^{-1}$, because of charged monoenyl or cyclopentenyl species and charged naphthalene species. After that, the bands around 36000 and $25000 \mathrm{~cm}^{-1}$ are formed, which indicate that there are both neutral and charged aromatics present, which keep growing until the end of the reaction. These bands correspond well with the intermediates known from the hydrocarbon pool mechanism.

During the conversion of methanol over DDR, the bands at $34000 \mathrm{~cm}^{-1}$ and at $26000 \mathrm{~cm}^{-1}$ are visible in the beginning of the reaction at all reaction temperatures, similar to the beginning of the reaction in CHA. After a short period, the bands at 36000 and $25000 \mathrm{~cm}^{-1}$ are formed, which keep growing until the end of the reaction. The band around $25000 \mathrm{~cm}^{-1}$ has a remarkably sharp shoulder around $24800 \mathrm{~cm}^{-1}$, which indicates that there is a narrow distribution of hydrocarbon species contributing to this band. Using the GC/MS analysis of the retained species described above, this feature was assigned to charged 1-methylnaphthalene, which is clearly formed preferentially in the DDR cage. At a reaction temperature of $350{ }^{\circ} \mathrm{C}$, the formation of 1-methylnaphthalene indicates the start of the deactivation of the catalyst, while at 400 and $450{ }^{\circ} \mathrm{C}$, the catalyst remains active when this species is formed.

The development of spectral features in the LEV zeolite starts similar to the operando UV-vis spectra of CHA and DDR, with the formation of absorption bands related to monoenyl species and alkylated benzene. However, later in the reaction, the intensity of the absorption bands stays much lower, and the shape of the feature around $25000 \mathrm{~cm}^{-1}$ much less pronounced. This makes specific spectral assignments of the observed features challenging. Similar to DDR, the formation of a sharp feature at
$24800 \mathrm{~cm}^{-1}$ in LEV is correlated with deactivation at a reaction temperature of $350{ }^{\circ} \mathrm{C}$, but not at higher reaction temperatures.

The fact that the exact shape of the operando UV-vis spectra differs significantly between the different zeolites means that, although all three zeolites consist of relatively large cages that are interconnected by eight-ring windows, different retained hydrocarbons are present during MTO, which is a result of the difference in the size and shape of the cages, since the other properties of the samples are very comparable. For CHA, the absorbance in the entire spectral region is much higher than for DDR and LEV, and the spectral features are broader. This indicates that the CHA zeolite contains more retained hydrocarbons and also a broader distribution of species than DDR and LEV. This corresponds well with the observations in the GC/MS and TGA analysis of the retained hydrocarbons.

3.5. Deconvolution of UV-vis Spectra and Chemometrics. In order to get more specific information on the band positions from the broad and often convoluted bands in the operando UV-vis spectra, for every experiment, five spectra were selected for deconvolution (i.e., one during the induction period, two during the active period and two during deactivation). The broad bands in these spectra were deconvoluted by fitting the spectrum with Gaussian curves using the program Fityk. ${ }^{57}$ As mentioned before, an increase in absorbance over the complete range of wavenumbers was observed for all experiments, indicating the formation of extended coke deposits located at the external surface of the material. To improve the quality of the deconvolutions, this general darkening was removed from the spectrum by the subtraction of the absorbance value at $12500 \mathrm{~cm}^{-1}$ as a baseline. More details about the deconvolution procedure, along with all deconvoluted UV-vis spectra can be found in the Supporting Information (Figures S5-S7).

During methanol conversion over the CHA zeolite, a band between 24400 and $25800 \mathrm{~cm}^{-1}$ is present at all temperatures and during all phases of the reaction (green Gaussian). This band has been assigned to highly methylated benzene carbocations, which are active species in the MTO process. ${ }^{31,34,58}$ These species are also observed in the GC/MS of the retained hydrocarbons. Also, a band between 15500 and $17500 \mathrm{~cm}^{-1}$ is observed in all experiments (blue Gaussian), indicating the presence of polyaromatic species. ${ }^{29,31,34,37,59,60}$ The region between 28000 and $40000 \mathrm{~cm}^{-1}$ is very convoluted and contains almost no features, which makes it impossible to deconvolute it very accurately. The region is a convolution of at least three bands, caused by the presence of neutral aromatics and monoenyl, dienyl, and cyclopentenyl carbocations. ${ }^{22,56,61,62}$ 
a)

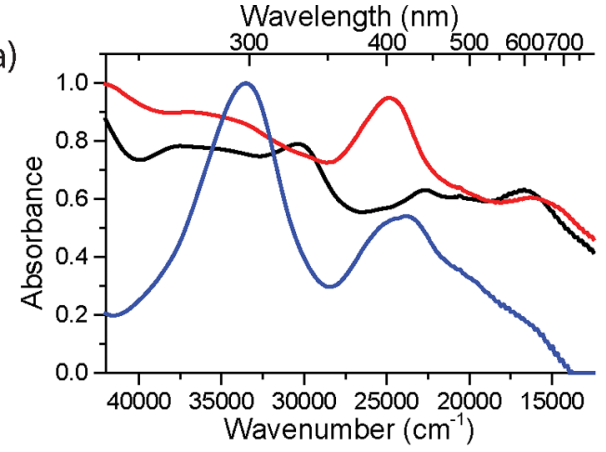

b)
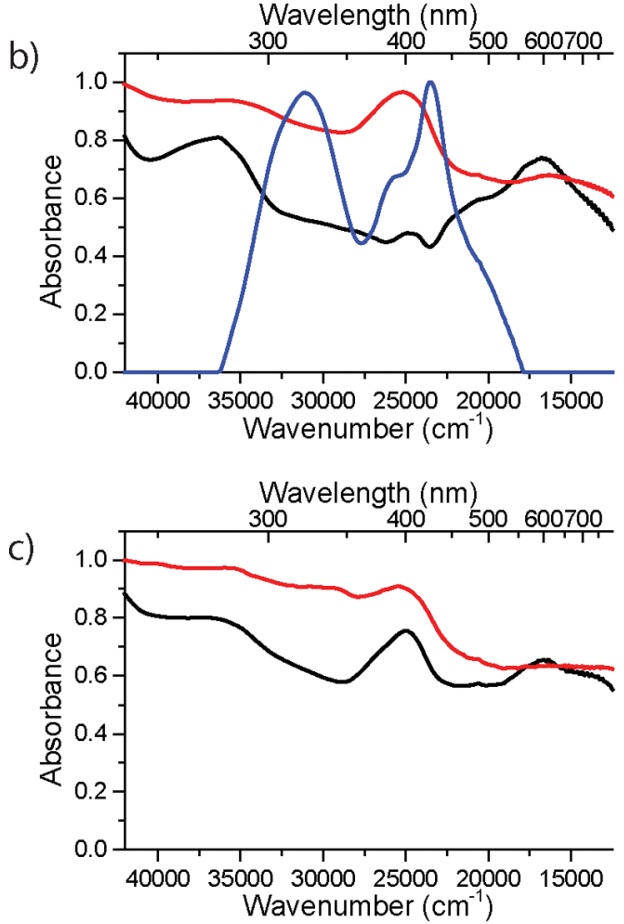
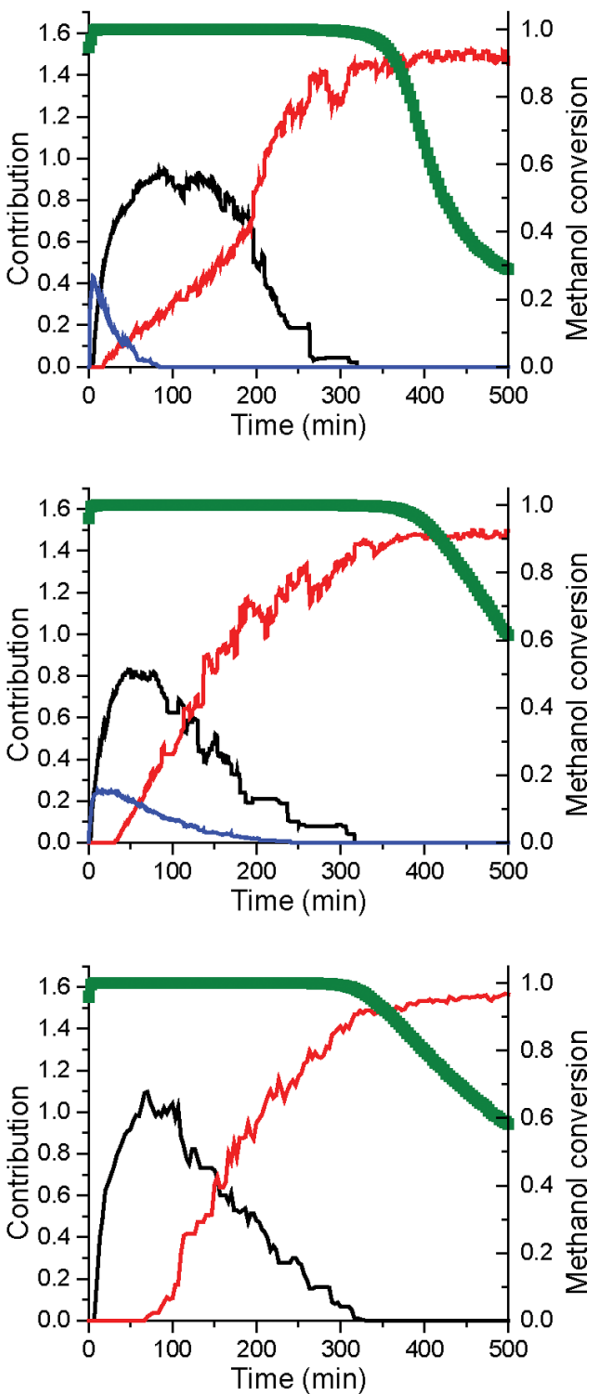

Figure 5. (left) MCR-ALS components and (right) their respective contributions to the overall operando UV-vis spectra vs time for the conversion of methanol over CHA zeolite at a reaction temperature of (a) $350^{\circ} \mathrm{C}$, (b) $400^{\circ} \mathrm{C}$, and (c) $450^{\circ} \mathrm{C}$. The colors of the contribution plots correspond to the colors of the components.

For DDR, the operando UV-vis spectra are dominated by a sharp band around $25000 \mathrm{~cm}^{-1}$. This band is a convolution of a band between 25500 and $26000 \mathrm{~cm}^{-1}$ (green Gaussian), which originates from methylated benzene carbocations, and a very sharp band around 24500-24800 $\mathrm{cm}^{-1}$ (orange Gaussian). Based on the dominant presence of this band in the UV-vis region of the spectrum and the large amount of 1-methylnaphthalene in the GC/MS of the retained material, we assign this UV-vis feature to protonated 1-methylnaphthalene, as described before. Diamantane, which according to GC/MS is also present in the catalyst at low temperatures, absorbs light in the deep-UV region around $51600 \mathrm{~cm}^{-1}$, so this will not visible with the UV-vis spectrometer used for this work. ${ }^{63}$ The band at $20000 \mathrm{~cm}^{-1}$ (blue Gaussian) is due to polyaromatics, and in the case of DDR, the features in the region between 28000 and $40000 \mathrm{~cm}^{-1}$ are a convolution of at least two bands: a small band around $31000 \mathrm{~cm}^{-1}$ from monoenyl or charged cyclopentenyl species and a large band around $36000 \mathrm{~cm}^{-1}$ from neutral aromatic species.

In LEV, the band around $26000 \mathrm{~cm}^{-1}$ (green Gaussian) is also present and at reaction temperatures of 400 and $450{ }^{\circ} \mathrm{C}$, the sharp feature around $24600 \mathrm{~cm}^{-1}$ (orange Gaussian) indicating the presence of 1-methylnaphthalene is also found, but the absorbance and the contribution to the overall spectrum is much lower than that for DDR. The band below $30000 \mathrm{~cm}^{-1}$ is very convoluted and has contributions from naphthalenic and polyaromatic species. These species most likely reside outside the zeolite crystal, because they do not fit inside the LEV cages.

In order to study the kinetic evolution of the retained hydrocarbons inside the zeolites in more detail, the time evolution of the operando UV-vis spectra was analyzed using Multivariate Curve Resolution (MCR). This chemometric analysis was performed using the MCR-ALS toolbox, ${ }^{64}$ which performs a deconvolution of the data matrix of the complete time series of UV-vis spectra into contributions of pure components. (They are not necessarily pure chemical phases or species.) Similar to Principal Component Analysis (PCA), MCR provides a decomposition that maximizes the explained variance in the data, but allows defining constraints for the obtained components. The constraints can then be chosen to be physically or chemically meaningful, such as non-negativity and unimodality of the obtained components (a component here means a set of UV-vis spectral features that show the same time behavior). Using this method and the terminology typically used in PCA, 
a)

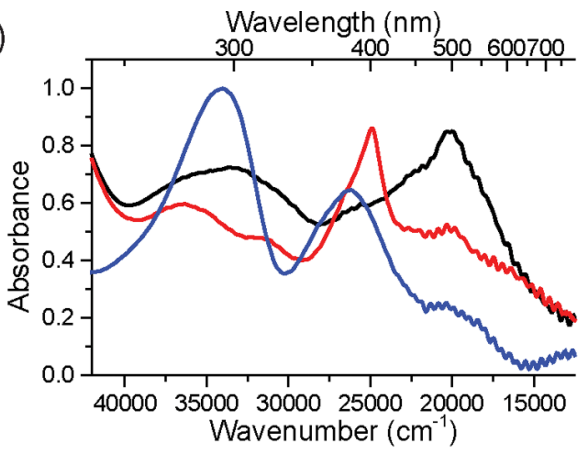

b)

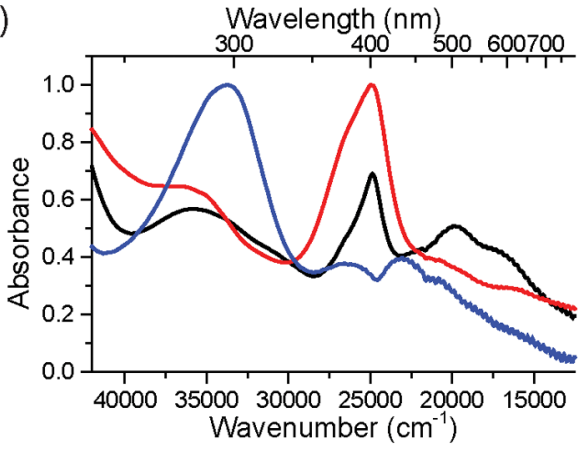

c)

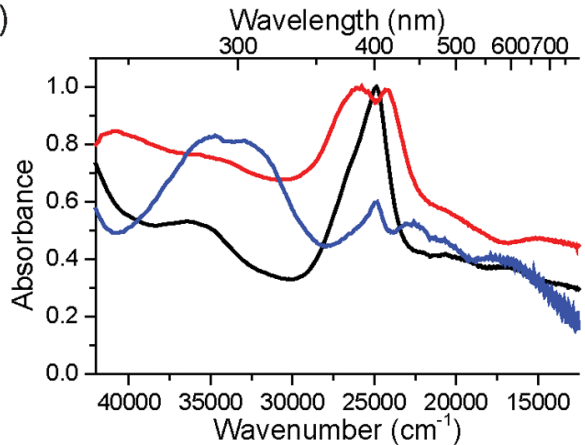

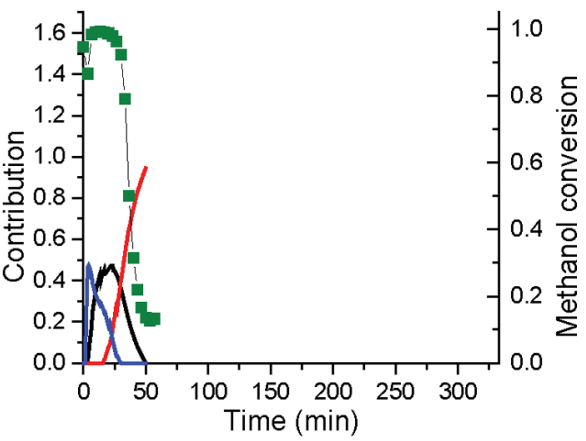
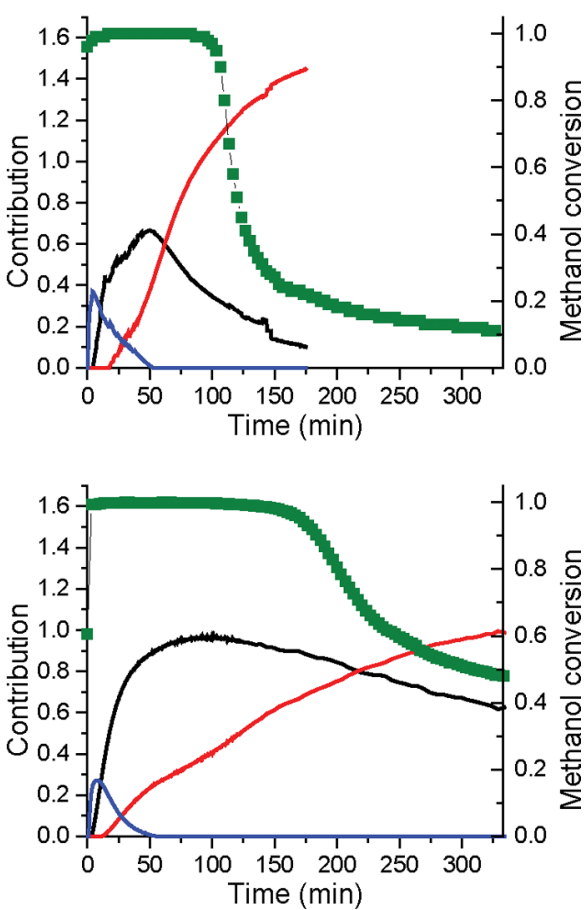

Figure 6. (left) MCR-ALS components and (right) their respective contributions to the overall operando UV-vis spectra vs time for the conversion of methanol over DDR zeolite at a reaction temperature of (a) $350{ }^{\circ} \mathrm{C}$, (b) $400^{\circ} \mathrm{C}$, and (c) $450{ }^{\circ} \mathrm{C}$. The colors of the contribution plots correspond to the colors of the components.

the time series of the operando UV-vis spectra was split into two parts: components, i.e. UV-vis spectral features that follow the same kinetics during the reaction, and the contributions of these components versus time. An initial estimate of the contributions was made using Evolving Factor Analysis. ${ }^{64}$ Because it is unlikely that a group of species that has disappeared during the reaction reappears later in the reaction, a unimodality constraint was imposed on the contributions of components over time. Also, a non-negativity constraint was applied. As in PCA, summing up all components multiplied by their corresponding contributions results in a reconstruction of the original operando UV-vis spectra. The number of components needed to describe the original data set to a specific precision can be checked by inspecting the cumulative variance explained (CVE) by the chosen components. For an accurate reconstruction (CVE > 99.9\%) of the original spectra, three components were needed in most cases.

The components and contributions for CHA, DDR, and LEV are shown in Figures 5-7. The time behavior of the contributions is similar for all experiments. At the beginning of the reaction, when the methanol conversion is almost immediately $100 \%$, there is an immediate formation of absorbing species, which is represented by the blue component. After some time, while the catalyst remains active, a second group of spectral features, represented by the black component becomes dominant in the operando UV-vis spectra. With time-on-stream, the spectral features represented by the red component increase until the catalyst starts deactivating. At the moment that the catalyst is fully deactivated, the overall UV-vis spectrum is almost identical to the red component. Because the UV-vis spectra are an average over the whole catalyst bed and since some species can be present during the entire reaction, the different components can have some overlap. However, there are clear differences between the components that can be used in combination with their contributions to describe the evolution of the retained hydrocarbon pool species over time.

In the case of CHA, at reaction temperatures of 350 and $400{ }^{\circ} \mathrm{C}$, the blue component that is dominant in the beginning of the reaction contains two bands around $35000 \mathrm{~cm}^{-1}$ and $25000 \mathrm{~cm}^{-1}$, which can be assigned to monoenyl carbocations and alkylated benzene carbocations, respectively. These are species that can be correlated with the formation of the hydrocarbon pool inside the zeolite, i.e., the induction period. At a reaction temperature of $450{ }^{\circ} \mathrm{C}$, only two components were enough to reconstruct the original spectra $(\mathrm{CVE}>99.9 \%)$, which behave similarly in time 

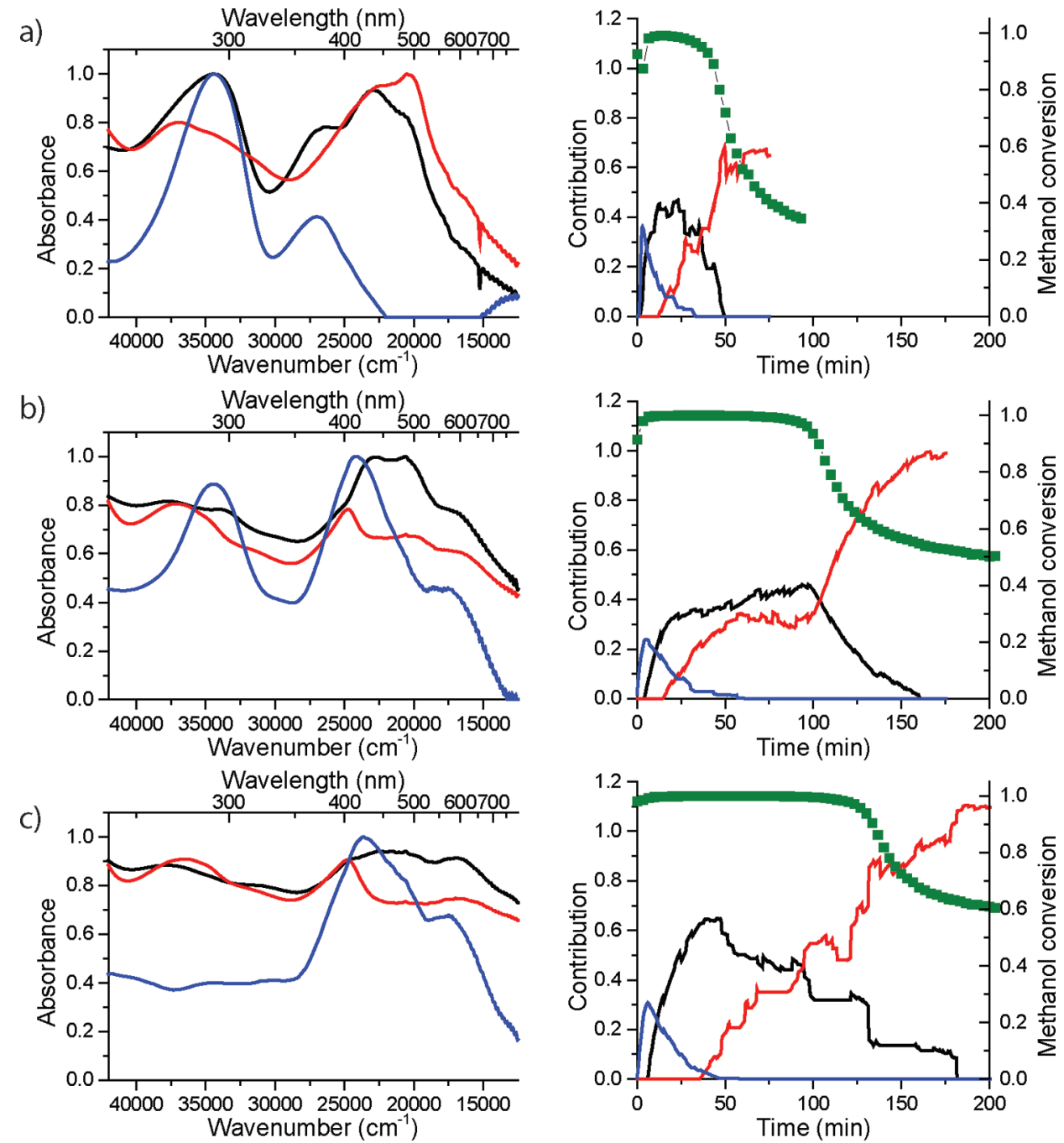

Figure 7. (left) MCR-ALS components and (right) their respective contributions to the overall operando UV-vis spectra vs time for the conversion of methanol over LEV zeolite at a reaction temperature of (a) $350^{\circ} \mathrm{C}$, (b) $400^{\circ} \mathrm{C}$, and (c) $450{ }^{\circ} \mathrm{C}$. The colors of the contribution plots correspond to the colors of the components.

to the black and red components at lower temperatures. This indicates that at this reaction temperature, the induction period species develop into the active species faster. The broad feature around $25000 \mathrm{~cm}^{-1}$ is visible in the black component at a reaction temperature of $450{ }^{\circ} \mathrm{C}$, which is dominant during the active period, whereas at reaction temperatures of 350 and $400{ }^{\circ} \mathrm{C}$, this feature is part of the red component, which is correlated with deactivation.

For DDR at all reaction temperatures, the blue component that is dominant in the beginning of the reaction mainly contains a band at $34000 \mathrm{~cm}^{-1}$, which can be assigned to monoenyl carbocations. These monoenyl species can be correlated with the formation of the hydrocarbon pool inside the zeolite, i.e., the induction period. The black component is present during the active period of the reaction. It consists of a broad spectral feature below $35000 \mathrm{~cm}^{-1}$ from neutral HP species, and it has sharper features around $20000 \mathrm{~cm}^{-1}$. At 400 and $450{ }^{\circ} \mathrm{C}$, a sharp feature at $24500-24800 \mathrm{~cm}^{-1}$ ascribed to 1-methylnaphthalene is visible in the black component during the active period of the reaction, indicating that 1-methylnaphthalene acts as an active species in the MTO process at these reaction temperatures. Methylated naphthalenes have been shown to be active species for MTO in various other studies, both experimental and theoretical. ${ }^{65-67}$ At $350{ }^{\circ} \mathrm{C}$ this feature is present in the red component, which means that 1-methylnaphthalene is a deactivating species at $350{ }^{\circ} \mathrm{C}$, in contrast to its role at higher reaction temperatures. The red components for the reaction temperatures of 400 and $450{ }^{\circ} \mathrm{C}$ contain very similar spectral features, but at the higher reaction temperature it grows faster.

In the case of LEV, the different components are less wellresolved than those for the other two zeolite materials, making it challenging to observe a general trend with changing of the reaction temperature. This is likely caused by the high degree of convolution and lack of clear features in the operando UV-vis spectra. However, the general trend in the contributions of the different components with time-on-stream is similar to the other frameworks.

3.6. Proposed Deactivation Mechanism. Using the kinetics of the formation of different species described by the chemometric analysis, it is possible to follow the evolution of the retained hydrocarbon pool species using operando UV-vis spectroscopy. The three distinct components represent the species that are predominant during the three stages of the MTO process, which are schematically drawn in Figure 8:

Stage I: Induction period

Stage II: Active period

Stage III: Deactivation 


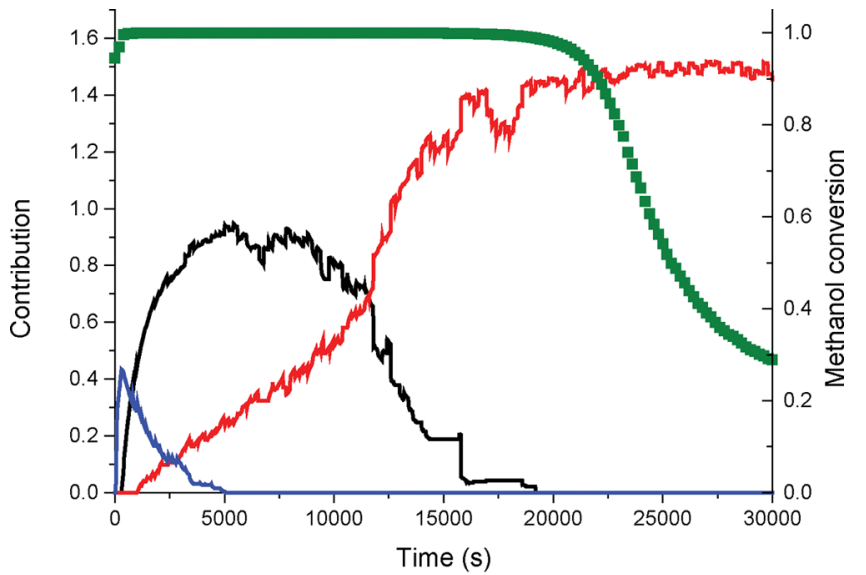

Induction period

Active period

Deactivation

Figure 8. Proposed model to explain the different stages of the Methanol-to-Olefins (MTO) reaction over the three different zeolite framework structures under study.

Combining this with the bulk chemical analysis of the deactivated catalysts, a deactivation model can be proposed for the three different zeolites at different reaction temperatures. Figure 9 shows a schematic overview of the deactivation by carbonaceous deposits in the different zeolite crystals after conversion of methanol at different reaction temperatures, based on the analysis of the coke by TGA and GC/MS, combined with the chemometric results. The squares represent individual zeolite crystals, and the colors indicate which species are present in the different regions of the crystal.
TGA results for $\mathrm{CHA}$ catalysts show that at reaction temperatures of 350 and $400{ }^{\circ} \mathrm{C}$ the deactivated catalyst contains both external coke and carbonaceous deposits inside all cages. At these reaction temperatures, the catalyst deactivates when the broad feature around $25000 \mathrm{~cm}^{-1}$ becomes more dominant in the UV-vis spectrum, i.e., when all pores become filled with methylated naphthalene species. At a reaction temperature of $450{ }^{\circ} \mathrm{C}$, a lower amount of carbonaceous deposits is detected in the deactivated catalyst using TGA. The feature around $25000 \mathrm{~cm}^{-1}$ is part of the black component, which means that it represents active species rather than deactivating species. At this reaction temperature, deactivation of the catalyst is due to the formation of external coke.

At $350{ }^{\circ} \mathrm{C}$, DDR deactivates when 1-methylnaphthalene is formed, which at that temperature is not active in performing the MTO reaction. Also, inactive diamantane species are formed. At the moment these species are formed, they block access to the center of the catalyst particle, which results in the catalyst particles not being completely filled with carbonaceous deposits when the catalyst is deactivated. The effect of the deactivation of catalysts by blockage of pores at the outside of the crystal has been observed as well in previous studies, in which large zeolite crystals were used for the MTO process. ${ }^{27,35,37}$ At reaction temperatures of 400 and $450{ }^{\circ} \mathrm{C}$, 1-methylnaphthalene is an active species, and deactivation of the catalyst occurs when all of the cages of the zeolite are filled, preventing methanol and products to reach the active species to continue the conversion of methanol into olefins. Previous studies have shown that methylated naphthalenes can be active species in MTO, but with higher energy barriers than methylated benzene. ${ }^{67}$ The energy barriers for methylation and dealkylation of hydrocarbon pool species have a strong influence on the reaction rate in MTO and can have a different value in different zeolite frameworks. ${ }^{31,68}$

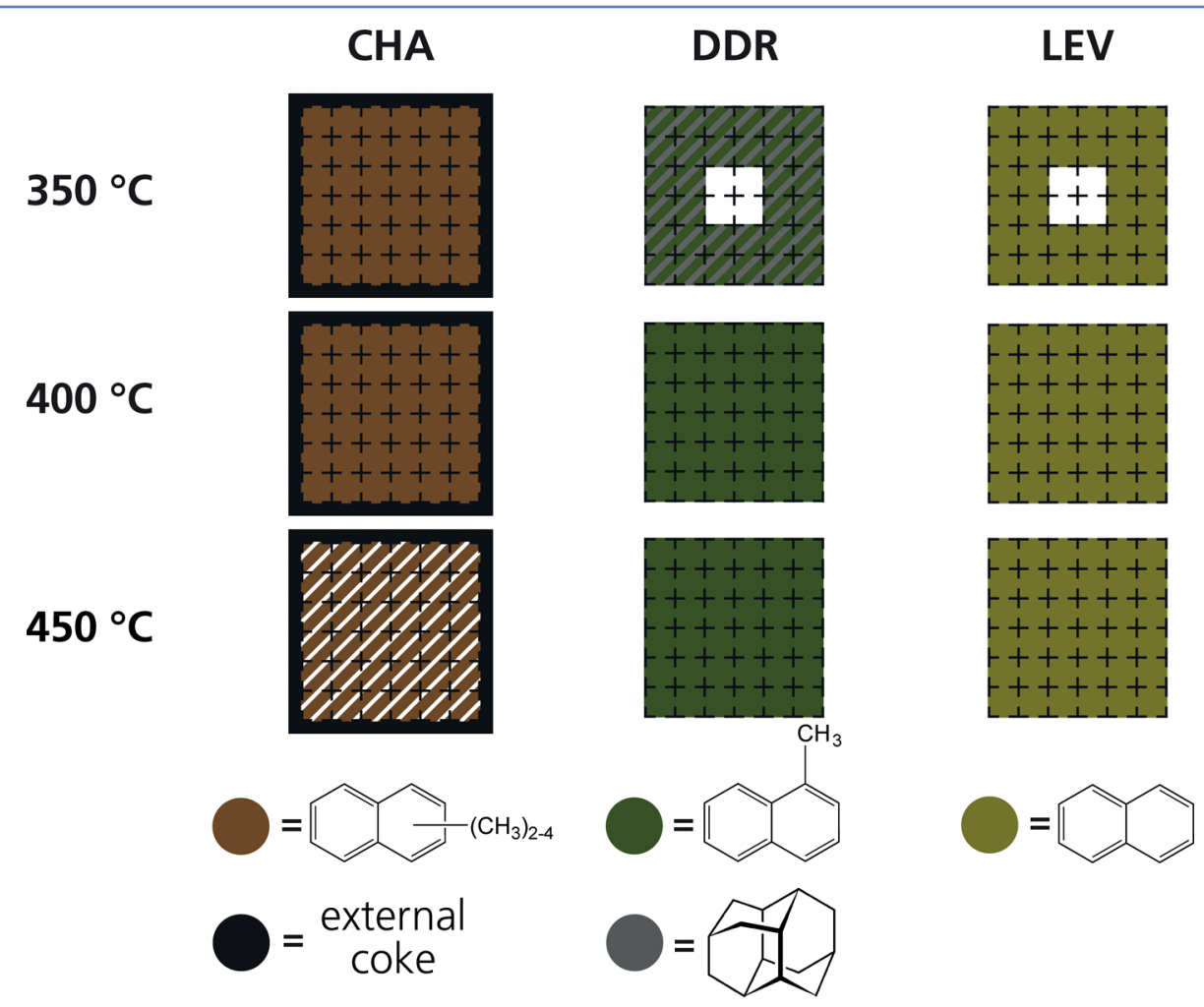

Figure 9. Schematic of the type of deactivation by carbonaceous deposits throughout the different zeolite crystals at different reaction temperatures. 
This could explain the effect of the applied reaction temperature on the activity of 1-methylnaphthalene, indicating that higher reaction temperatures are needed to make the methylation of 1-methylnaphthalene and subsequent dealkylation possible. Another explanation for the dependence on reaction temperature is that diffusion is more difficult in the 2-D DDR pore network than in the 3-D CHA framework.

The deactivation of LEV is similar to that of DDR. At $350{ }^{\circ} \mathrm{C}$, the pores of the deactivated catalyst are not completely filled, while this is the case at 400 and $450{ }^{\circ} \mathrm{C}$. Similarly to DDR, the dependence on reaction temperature is also expected to originate from high activation energies of some of the active species and the fact that diffusion is more difficult in the 2-D LEV pore network than in the 3-D CHA framework. Because the LEV cage is smaller than the cages of the other two frameworks, larger HP species do not fit in the LEV framework, which explains the faster deactivation and the smaller species found in GC/MS analysis of the extracted species.

To verify whether species that are deactivating at a lower reaction temperature indeed become active at higher reaction temperatures, temperature-programmed experiments were performed. Methanol was converted at a reaction temperature of $350{ }^{\circ} \mathrm{C}$ until the start of deactivation, after which the reaction temperature was increased to $400{ }^{\circ} \mathrm{C}$, and subsequently to $450^{\circ} \mathrm{C}$. The resulting activity data and UV-vis spectra are shown in Figures S8-S10. It is visible that upon increasing the reaction temperature, activity is restored for a short period of time. This effect, called reanimation, has been observed before for MFI catalysts and occurs due to the dealkylation of aromatic species that were alkylated at lower reaction temperatures. ${ }^{5}$ The reanimation is most pronounced for the DDR zeolite when the reaction temperature is increased from 350 to $400{ }^{\circ} \mathrm{C}$. For $\mathrm{DDR}$, the reanimation period at $400{ }^{\circ} \mathrm{C}$ goes together with a large increase in absorbance in the UV-vis spectra. To a lesser extent this also holds for LEV, whereas the UV-vis spectra for $\mathrm{CHA}$ show only little change during the reanimation period. These results show that alkylated aromatics that are not active at low reaction temperatures can become active at higher reaction temperatures because the higher reaction temperature facilitates dealkylation reactions of these species. In the case of DDR and $\mathrm{LEV}$, this also results in a more extensive filling of the zeolite pore network with carbonaceous deposits, especially when going from 350 to $400{ }^{\circ} \mathrm{C}$, as can be seen from the large increase in UV-vis absorbance.

\section{CONCLUSIONS}

Three zeolite frameworks, namely, CHA, DDR, and LEV, consisting of large cages interconnected by eight-ring windows were compared in the MTO reaction. Using a combination of online product analysis and operando UV-vis spectroscopy during the reaction, along with bulk chemical analysis of the hydrocarbon deposits by GC/MS and TGA, mechanistic information was obtained. Although the pore structures of the three zeolite materials under comparison are similar in the way that they consist of large zeolite cages interconnected by eight-ring windows, it was shown that small differences in size and shape of the cages are responsible for a distinctly different nature of the hydrocarbon pool in the different frameworks. The results clearly show that in this way, the exact size and shape of the zeolite cages have a big influence on the mechanism and deactivation of catalysts during MTO. Additionally, the difference between the 2-D and 3-D pore networks also has a clear influence on catalyst deactivation.
In order to describe the evolution of the operando UV-vis spectra and thus to understand the evolution of the retained hydrocarbon pool species during the reaction, the operando UV-vis spectra were analyzed using multivariate analysis, in which three components and the contribution of these components to the overall spectrum were found to sufficiently describe the changes in the operando UV-vis spectra. The three obtained components represent the predominant spectral features during the induction period, active period, and the period where the catalyst deactivates, respectively. By varying the reaction temperature, it could be established that whereas the nature of the retained hydrocarbons depends mainly on the framework, the role of certain HP species (active or deactivating) can change depending on the temperature of the reaction, which influences the deactivation mechanism.

For CHA, at reaction temperatures of 350 and $400{ }^{\circ} \mathrm{C}$, formation of external coke is observed, but deactivation occurs once all pores are filled with naphthalene species. At a reaction temperature of $450{ }^{\circ} \mathrm{C}$, formation of external coke is also observed and the catalyst deactivates before all pores are filled with naphthalene species, indicating that at that reaction temperature deactivation is mainly caused by the external coke.

The role of 1-methylnaphthalene in DDR is deactivating at $350{ }^{\circ} \mathrm{C}$, but it acts as an active species at 400 and $450{ }^{\circ} \mathrm{C}$, probably due to a high activation energy of the reaction pathway involving 1-methylnaphthalene as active species. This causes the DDR catalyst to deactivate upon formation of these naphthalenic species at $350{ }^{\circ} \mathrm{C}$. Additionally, at this reaction temperature, diamantane is formed, which also contributes to the deactivation of the catalyst. These deactivating species form in the outer regions of the zeolite crystal, preventing access to the center of the catalyst particles. Because of that, the spent catalyst is not completely filled with carbonaceous deposits after performing the MTO process at $350{ }^{\circ} \mathrm{C}$. At 400 and $450{ }^{\circ} \mathrm{C}$, when 1 -methylnaphthalene is an active species, deactivation is caused by complete filling of the zeolite pores.

A trend similar to that for DDR is observed in the deactivation of the LEV catalyst. Species that are deactivating and block the pores of the material at $350{ }^{\circ} \mathrm{C}$, act as active species at 400 and $450{ }^{\circ} \mathrm{C}$, resulting in the complete filling of the pores of the deactivated material at the higher reaction temperatures.

\section{ASSOCIATED CONTENT}

\section{Supporting Information}

The Supporting Information is available free of charge on the ACS Publications website at DOI: 10.1021/acscatal.6b03677.

SEM micrographs, $\mathrm{NH}_{3}$-TPD profiles, IR spectra before and after $\mathrm{CO}$ adsorption, paraffin yields, deconvolution results of selected operando UV-vis spectra, and temperatureprogrammed experiments (PDF)

\section{AUTHOR INFORMATION}

\section{Corresponding Author}

*E-mail: B.M.Weckhuysen@uu.nl.

ORCID

Jorge Gascon: 0000-0001-7558-7123

Freek Kapteijn: 0000-0003-0575-7953

Bert M. Weckhuysen: 0000-0001-5245-1426

Notes

The authors declare no competing financial interest. 


\section{ACKNOWLEDGMENTS}

This research received funding from The Netherlands Organisation for Scientific Research (NWO) in the framework of the TASC Technology Area "Syngas, a Switch to Flexible New Feedstock for the Chemical Industry (TA-Syngas)". For performing the TGA experiments, the authors would like to thank Marjan Versluijs-Helder (Utrecht University, UU). Pascal Wijten (UU) is acknowledged for his assistance with the GC/MS analysis of the extracted coke.

\section{REFERENCES}

(1) Galli, P.; Vecellio, G. J. Polym. Sci., Part A: Polym. Chem. 2004, 42, 396-415.

(2) Corma, A.; Melo, F. V.; Sauvanaud, L.; Ortega, F. Catal. Today 2005, 107-108, 699-706.

(3) Olsbye, U.; Svelle, S.; Bjørgen, M.; Beato, P.; Janssens, T. V. W.; Joensen, F.; Bordiga, S.; Lillerud, K. P. Angew. Chem., Int. Ed. 2012, 51, 5810-5831.

(4) Bleken, F. L.; Skistad, W.; Barbera, K.; Kustova, M.; Bordiga, S.; Beato, P.; Lillerud, K. P.; Svelle, S.; Olsbye, U. Phys. Chem. Chem. Phys. 2011, 13, 2539-2549.

(5) Schulz, H.; Wei, M. Top. Catal. 2014, 57, 683-692.

(6) Bhawe, Y.; Moliner-Marin, M.; Lunn, J. D.; Liu, Y.; Malek, A.; Davis, M. ACS Catal. 2012, 2, 2490-2495.

(7) Kumita, Y.; Gascon, J.; Stavitski, E.; Moulijn, J. A.; Kapteijn, F. Appl. Catal., A 2011, 391, 234-243.

(8) Chen, J.; Li, J.; Wei, Y.; Yuan, C.; Li, B.; Xu, S.; Zhou, Y.; Wang, J.; Zhang, M.; Liu, Z. Catal. Commun. 2014, 46, 36-40.

(9) Masih, D.; Imai, H.; Yokoi, T.; Kondo, J. N.; Tatsumi, T. Catal. Commun. 2013, 37, 1-4.

(10) Park, J. W.; Lee, J. Y.; Kim, K. S.; Hong, S. B.; Seo, G. Appl. Catal., A 2008, 339, 36-44.

(11) Ji, Y.; Birmingham, J.; Deimund, M. A.; Brand, S. K.; Davis, M. E. Microporous Mesoporous Mater. 2016, 232, 126-137.

(12) Moliner, M.; Martínez, C.; Corma, A. Chem. Mater. 2014, 26, 246-258.

(13) Martínez-Franco, R.; Li, Z.; Martinez-Triguero, J.; Moliner, M.; Corma, A. Catal. Sci. Technol. 2016, 6, 2796-2806.

(14) Skistad, W.; Teketel, S.; Bleken, F. L.; Beato, P.; Bordiga, S.; Nilsen, M. H.; Olsbye, U.; Svelle, S.; Lillerud, K. P. Top. Catal. 2014, 57, 143-158.

(15) Li, J.; Wei, Y.; Chen, J.; Xu, S.; Tian, P.; Yang, X.; Li, B.; Wang, J.; Liu, Z. ACS Catal. 2015, 5, 661-665.

(16) Deimund, M. A.; Schmidt, J. E.; Davis, M. E. Top. Catal. 2015, 58, 416-423.

(17) Yarulina, I.; Goetze, J.; Gücüyener, C.; van Thiel, L.; Dikhtiarenko, A.; Ruiz-Martinez, J.; Weckhuysen, B. M.; Gascon, J.; Kapteijn, F. Catal. Sci. Technol. 2016, 6, 2663-2678.

(18) Dahl, I. M.; Kolboe, S. Catal. Lett. 1993, 20, 329-336.

(19) Wang, C.-M.; Wang, Y.-D.; Xie, Z.-K. J. Catal. 2013, 301, 8-19.

(20) Ilias, S.; Bhan, A. ACS Catal. 2013, 3, 18-31.

(21) Dai, W.; Wang, C.; Dyballa, M.; Wu, G.; Guan, N.; Li, L.; Xie, Z.; Hunger, M. ACS Catal. 2015, 5, 317-326.

(22) Wulfers, M. J.; Jentoft, F. C. ACS Catal. 2014, 4, 3521-3532.

(23) Olsbye, U.; Svelle, S.; Lillerud, K. P.; Wei, Z. H.; Chen, Y. Y.; Li, J. F.; Wang, J. G.; Fan, W. Chem. Soc. Rev. 2015, 44, 7155-7176.

(24) Chen, D.; Moljord, K.; Holmen, A. Microporous Mesoporous Mater. 2012, 164, 239-250.

(25) Qian, Q.; Vogt, C.; Mokhtar, M.; Asiri, A. M.; Al-Thabaiti, S. A.; Basahel, S. N.; Ruiz-Martínez, J.; Weckhuysen, B. M. ChemCatChem 2014, 6, 3396-3408.

(26) Park, J. W.; Seo, G. Appl. Catal., A 2009, 356, 180-188.

(27) Aramburo, L. R.; de Smit, E.; Arstad, B.; van Schooneveld, M. M.; Sommer, L.; Juhin, A.; Yokosawa, T.; Zandbergen, H. W.; Olsbye, U.; de Groot, F. M. F.; Weckhuysen, B. M. Angew. Chem., Int. Ed. 2012, 51, $3616-3619$.
(28) Aramburo, L. R.; Teketel, S.; Svelle, S.; Bare, S. R.; Arstad, B.; Zandbergen, H. W.; Olsbye, U.; de Groot, F. M. F.; Weckhuysen, B. M. J. Catal. 2013, 307, 185-193.

(29) Borodina, E.; Meirer, F.; Lezcano-González, I.; Mokhtar, M.; Asiri, A. M.; Al-Thabaiti, S. A.; Basahel, S. N.; Ruiz-Martinez, J.; Weckhuysen, B. M. ACS Catal. 2015, 5, 992-1003.

(30) Jiang, Y.; Huang, J.; Reddy Marthala, V. R.; Ooi, Y. S.; Weitkamp, J.; Hunger, M. Microporous Mesoporous Mater. 2007, 105, 132-139.

(31) Van Speybroeck, V.; Hemelsoet, K.; De Wispelaere, K.; Qian, Q.; Van der Mynsbrugge, J.; De Sterck, B.; Weckhuysen, B. M.; Waroquier, M. ChemCatChem 2013, 5, 173-184.

(32) Mores, D.; Stavitski, E.; Kox, M. H. F.; Kornatowski, J.; Olsbye, U.; Weckhuysen, B. M. Chem. - Eur. J. 2008, 14, 11320-11327.

(33) De Wispelaere, K.; Wondergem, C. S.; Ensing, B.; Hemelsoet, K.; Meijer, E. J.; Weckhuysen, B. M.; Van Speybroeck, V.; Ruiz-Martínez, J. ACS Catal. 2016, 6, 1991-2002.

(34) Hemelsoet, K.; Qian, Q.; De Meyer, T.; De Wispelaere, K.; De Sterck, B.; Weckhuysen, B. M.; Waroquier, M.; Van Speybroeck, V. Chem. - Eur. J. 2013, 19, 16595-16606.

(35) Qian, Q.; Ruiz-Martínez, J.; Mokhtar, M.; Asiri, A. M.; AlThabaiti, S. A.; Basahel, S. N.; van der Bij, H. E.; Kornatowski, J.; Weckhuysen, B. M. Chem. - Eur. J. 2013, 19, 11204-11215.

(36) Mores, D.; Stavitski, E.; Verkleij, S. P.; Lombard, A.; Cabiac, A.; Rouleau, L.; Patarin, J.; Simon-Masseron, A.; Weckhuysen, B. M. Phys. Chem. Chem. Phys. 2011, 13, 15985-15994.

(37) Mores, D.; Kornatowski, J.; Olsbye, U.; Weckhuysen, B. M. Chem. - Eur. J. 2011, 17, 2874-2884.

(38) Hofmann, J. P.; Mores, D.; Aramburo, L. R.; Teketel, S.; Rohnke, M.; Janek, J.; Olsbye, U.; Weckhuysen, B. M. Chem. - Eur. J. 2013, 19, $8533-8542$

(39) Stewart, A.; Johnson, D. W.; Shannon, M. D. Stud. Surf. Sci. Catal. 1988, 37, 57-64.

(40) Stewart, A. Zeolite Synthesis. EP 0255770, 1988.

(41) Zhu, Q.; Kondo, J. N.; Ohnuma, R.; Kubota, Y.; Yamaguchi, M.; Tatsumi, T. Microporous Mesoporous Mater. 2008, 112, 153-161.

(42) Yarulina, I.; Dikhtiarenko, A.; Kapteijn, F.; Gascon, J. Catal. Sci. Technol. 2017, 7, 300-309.

(43) Stewart, A. Zeolite Sigma-1. GB 2,193,202, 1988.

(44) De Lange, M. F.; Vlugt, T. J. H.; Gascon, J.; Kapteijn, F. Microporous Mesoporous Mater. 2014, 200, 199-215.

(45) Nijhuis, T. A.; Tinnemans, S. J.; Visser, T.; Weckhuysen, B. M. Phys. Chem. Chem. Phys. 2003, 5, 4361-4365.

(46) Sattler, J. J. H. B.; Beale, A. M.; Weckhuysen, B. M. Phys. Chem. Chem. Phys. 2013, 15, 12095-12103.

(47) Tinnemans, S. J.; Kox, M. H. F.; Nijhuis, T. A.; Visser, T.; Weckhuysen, B. M. Phys. Chem. Chem. Phys. 2005, 7, 211-216.

(48) Lónyi, F.; Valyon, J. Microporous Mesoporous Mater. 2001, 47, 293-301.

(49) Knözinger, H.; Huber, S. J. Chem. Soc., Faraday Trans. 1998, 94, 2047-2059.

(50) Krishna, R.; van Baten, J. M. Phys. Chem. Chem. Phys. 2013, 15, 7994-8016.

(51) Deimund, M. A.; Harrison, L.; Lunn, J. D.; Liu, Y.; Malek, A.; Shayib, R.; Davis, M. E. ACS Catal. 2016, 6, 542-550.

(52) Baerlocher, C.; McCusker, L. B.Database of Zeolite Structures. http://www.iza-structure.org/databases/.

(53) Guisnet, M.; Magnoux, P. Appl. Catal. 1989, 54, 1-27.

(54) Guisnet, M.; Magnoux, P. Appl. Catal., A 2001, 212, 83-96.

(55) Wei, Y.; Li, J.; Yuan, C.; Xu, S.; Zhou, Y.; Chen, J.; Wang, Q.; Zhang, Q.; Liu, Z. Chem. Commun. 2012, 48, 3082-3084.

(56) Kiricsi, I.; Förster, H.; Tasi, G.; Nagy, J. B. Chem. Rev. 1999, 99, 2085-2114.

(57) Wojdyr, M. J. Appl. Crystallogr. 2010, 43, 1126-1128.

(58) Bjørgen, M.; Bonino, F.; Kolboe, S.; Lillerud, K.-P.; Zecchina, A.; Bordiga, S. J. Am. Chem. Soc. 2003, 125, 15863-15868.

(59) Palumbo, L.; Bonino, F.; Beato, P.; Bjørgen, M.; Zecchina, A.; Bordiga, S. J. Phys. Chem. C 2008, 112, 9710-9716. 
(60) Qian, Q.; Ruiz-Martínez, J.; Mokhtar, M.; Asiri, A. M.; AlThabaiti, S. A.; Basahel, S. N.; Weckhuysen, B. M. Catal. Today 2014, 226, 14-24.

(61) Dai, W.; Wu, G.; Li, L.; Guan, N.; Hunger, M. ACS Catal. 2013, 3, 588-596.

(62) Dai, W.; Wang, X.; Wu, G.; Guan, N.; Hunger, M.; Li, L. ACS Catal. 2011, 1, 292-299.

(63) Landt, L.; Klünder, K.; Dahl, J. E.; Carlson, R. M. K.; Möller, T.; Bostedt, C. Phys. Rev. Lett. 2009, 103, 47402.

(64) Jaumot, J.; de Juan, A.; Tauler, R. Chemom. Intell. Lab. Syst. 2015, $140,1-12$.

(65) Song, W.; Fu, H.; Haw, J. F. J. Phys. Chem. B 2001, 105, 1283912843.

(66) Haw, J. F.; Song, W.; Marcus, D. M.; Nicholas, J. B. Acc. Chem. Res. 2003, 36, 317-326.

(67) Hemelsoet, K.; Nollet, A.; Vandichel, M.; Lesthaeghe, D.; Van Speybroeck, V.; Waroquier, M. ChemCatChem 2009, 1, 373-378.

(68) Hill, I. M.; Hashimi, S. A.; Bhan, A. J. Catal. 2012, 285, 115-123. 